\title{
Predictors of chronic undernutrition (stunting) among under five children in rural east Wollega, oromiya region, west Ethiopia: a community based unmatched case - control study
}

\begin{abstract}
Background: Chronic childhood undernutrition (stunting) becomes an underlying cause of morbidity and mortality in children as well as increasing susceptibility to different diseases later in adolescents and adults. Thus the objective of the present study was to identify predictors of chronic undernutrition among children under five years aged in rural west Ethiopia as careful understanding of these factors will help to design appropriate interventions.
\end{abstract}

Methods: Community based case control study was conducted on 1038 (346 cases and 692 controls) samples of children under five years aged with their respective mothers from March to July, 2016. The data was collected through interview and anthropometric measurement. Odds ratio and 95\% CI (confidence interval) was estimated to identify predictors of stunting using multivariate logistic regression.

Results: the overall response rate was $94.5 \%$. Stunting was significantly associated with being male children [Adjusted Odds Ratio $(\mathrm{AOR})=2.45895 \% \mathrm{CI}=1.52,3.99$ ], high birth order $(\mathrm{AOR}=1.70795 \% \mathrm{CI}=1.02,2.857)$, narrow birth interval $(\mathrm{AOR}=4.6995 \% \mathrm{CI}=1.613$, 13.66), lack of ownership of farm land $(\mathrm{AOR}=1.69895 \% \mathrm{CI}=1.035,2.785)$, open field waste disposal, diarrhea $(\mathrm{AOR}=2.4495 \% \mathrm{CI}=1.42,4.19)$, short duration of breast feeding $((\mathrm{AOR}=2.1595 \% \mathrm{CI}=1.249,3.707)$ and use of bottle $(\mathrm{AOR}=2.4995 \% \mathrm{CI}=1.312,4.725)$ and hand $(\mathrm{AOR}=2.3995 \% \mathrm{CI}=1.226,4.67)$ for feeding of complementary foods.

Conclusions: Stunting was significantly associated with male sex, high birth order, narrow birth interval, lack of possession of agricultural land, poor sanitation, diarrhea, inappropriate IYCF (infant and young child feeding) practices like; short duration of breast feeding and mothers utilization of bottle and hand for feeding additional foods. Thus organized efforts aimed at improving sanitary condition and IYCF practices of the rural community is necessarily in order to tackle the problem of undernutrition in children. More over mothers needs to be encouraged to space births through use of family planning services.

Keywords: Ethiopia, east Wollega, under five children, chronic nutritional status, stunting
Volume 7 Issue 2 - 2017

\section{Amsalu Taye Wondemagegn, Melese Chego Cheme, Emiru Adeba Gerbi \\ Department of public health, Wollega University, Ethiopia}

Correspondence: Amsalu Taye Wondemagegn, College of Health Sciences, Department of public health, Lecturer of human Anatomy, Wollega University, Nekemte, Ethiopia, Tel +251921815441, Fax 0576617985, Email 50amsalu@gmail.com

Received: September 22, 2017 | Published: October 23, 2017
Abbreviations: AKs, administrative kebeles; ANC, anti natal care; BF, breast feeding; CF, complementary feeding; CI, confidence interval; DHS, demographic and health survey; EMDHS, Ethiopia mini demographic and health survey; H/A, height-for-age; HAZ, height for age z score; HHs, households; IYCF, infant and young child feeding; OR, odds ratio; AOR, adjusted odds ratio; SD, standard deviation; UNICEF, united nations children's fund; WHO, world health organization

\section{Introduction}

One form of undernutrition in children is chronic undernutrition (stunting), which refers to low height-for-age, which reflects a failure to reach linear growth potential as a result of suboptimal health and/ or nutritional conditions. ${ }^{1,2}$
Chronic under nutrition (stunting) is still significant public health problems mainly in least developed countries. According to previous nationwide study, the prevalence of stunting in developing countries was $38 \%$ in $2011 .^{3}$ In the same fashion a study found the prevalence of stunting among under five children in the horn of east Africa was $38 \%{ }^{4}$

Even if, stunting is in decreasing trend over the years, prevalence of stunting is still in serious condition in Ethiopia. According to Ethiopia Demographic and Health Survey (EDHS) 2011, 44\% of Ethiopian under five children were stunted and about $40 \%$ of under five children were stunted according to mini EDHS 2014 report. ${ }^{5,6}$

In the region of the study area, according to EDHS 2011, 41.4\% of under five children are stunted. ${ }^{5}$ In addition mini EDHS 2014 regional report showed $38.2 \%$ of under five children were stunted, and 
$18.6 \%$ severely stunted. ${ }^{6}$ This figure is much higher than the national as well as regional figures of wasting and underweight. As different literatures reported this highly prevalent problem becomes the causes of various morbidity and mortality conditions in under five children. For example in the horn of east Africa, it is estimated that about 5 million children die each year before reaching their fifth birthday as a result of subordinating effect of poor nutritional status on familiar communicable diseases. ${ }^{7}$ Contemporaneously in Ethiopia about $10 \%$ of children die each year before reaching their first birthday due to subordinating effect of poor nutritional status. ${ }^{8}$ Chronic under nutrition (stunting) has been associated with poor learning ability and low productivity, which intern had an effect on economic growth of a country. Moreover, chronic under nutrition (stunting) in childhood may be associated with adult stunting and which inter leads to have low birth weight babies thus, have an intergenerational impact. ${ }^{9,10}$

Various studies done in different area of Ethiopia showed the magnitude of chronic undernutrition but these studies do not provide sufficient evidence on those risk factors leading to chronic undernutrition. In addition previous local studies mainly try to show the association between socioeconomic and demographic factors such as family income/wealth status/, farm land, education status, family size, child's age and gender ${ }^{11-18}$ with chronic under nutrition through cross sectional survey. Only few studies were reported about the association between chronic undernutrition and risk factors like Infant and Young Child Feeding (IYCF) practices which includes pre-lacteal feeding, ${ }^{12,14}$ time of initiation of breast feeding, ${ }^{5}$ feeding of colostrum, ${ }^{12}$ duration of exclusive breast feeding, ${ }^{5,18}$ duration of breast feeding, ${ }^{5,14}$ age at complementary feeding, ${ }^{5,14}$ the type and frequency of complementary foods ${ }^{14}$ and methods of complementary feeding ${ }^{12,14,17}$ as well as environmental health state like water supply, sanitation and housing conditions. ${ }^{11,12,15,16}$ However, most of these surveys were conducted on insufficient number of study participants and used cross sectional study designs which are not appropriate to identify risk factors of chronic under nutrition (stunting).

Thus, the main objective of this study was to identify predictors of chronic undernutrition among children under five years aged in rural east Wollega, Oromiya region, West Ethiopia from March to July, 2016. Hence, the results of this study would help to know the contributing factors of the problem. Identifying the risk factors related with nutritional status of under five children in the study area would enable to guide public health planners and policy makers to design appropriate nutritional intervention programs to alleviate the problem and its associated consequences.

\section{Materials and methods}

\section{Study design and setting}

A community based case control study was employed to identify factors related to chronic nutritional status among children under five years aged in the study area by using quantitative research method. The study was conducted in East Wollega zone, west Ethiopia from March to July, 2016. East Wollega zone has a capital town of Nekemte. The town is located in western direction of Oromiya region about $328 \mathrm{~km}$ from Addis Ababa, the capital city of Ethiopia. The zone is formed by 17 Woreda; each of the Woreda is formed from many administrative Kebeles. For majority of the population, the livelihood depends directly or indirectly on agriculture.

\section{Study participants and variables}

The study populations was selected children under five years aged who have chronic undernutrition [Height for age $<-2$ SD (Standard Deviation)] for cases and selected children under five years aged who have not chronically undernourished (Height for age $\geq-2 \mathrm{SD}$ ) for controls, and their corresponding mothers/care givers. The study participants (both cases and controls) were identified by investigators prior to actual data collections and households with the cases and controls are marked through code.

The sample size was calculated using, two population proportion determination formulas on Epi Info version 3.5.1 statcalc, by using the following assumptions: proportion of illiteracy among the mothers of the controls to be $66.1 \%$ and of the cases $75.0 \%,{ }^{8} 95 \%$ confidence interval, $80 \%$ power of the study, control to case ratio of $2: 1$ to detect an odds ratio of $1.54,,^{15}$ the final sample size after adding $5 \%$ nonresponse rate is becoming 1039 (346 cases and 692 controls).

The sampling procedures used to select representative sample was multi-stage by using simple random sampling method. Representative Woreda in the zone was selected by lottery. Next, the representative administrative Kebeles (AKs) in each selected district was selected by lottery. In the selected AKs of the districts households having under five children was identified. The names of identified HHs having under five children was coded by number. Then this HHs was selected by random number in each study AKs of the districts proportionally. Selected subjects were first assessed for stunting.

a. The primary sampling unit was Woreda.

b. The secondary sampling unit was Kebeles.

c. The tertiary sampling unit was HHs having under five children

d. The study units was individuals (mother-child pairs)

The outcome variable of this study was chronic under nutritional status (stunting status) among selected under five children. Risk factors related to poor nutritional status were observed based on UNICEF's (United Nations Children's Fund) malnutrition conceptual framework. This factors are intertwined with each other and can be grouped and put in hierarchy as immediate (biological), underlying or behavioral and basic or structural risk factors depending on their proximate contribution for the occurrences of the problem under nutrition. Accordingly the most immediate risk factors are poor diet and disease which have direct influences on child nutritional status and which are themselves influenced by a set of underlying factors; household food security, maternal/ child caring practices and access to health services and healthy environment. These underlying factors themselves are influenced by the basic factors (socio-economic and political conditions).

\section{Instruments and measurements}

The data was collected using structured questionnaire and anthropometric measurements. The questionnaire was initially be prepared in English and then translated into the local language. Information regarding to socioeconomic and demographic factors, child factors, maternal factors and environmental health conditions was collected from mothers/caregivers by face to face interview. Anthropometric data was obtained by measuring height of children. Standing height for those who is 24 months and older was measured 
without any footwear to the nearest $0.1 \mathrm{~cm}$ using a standard calibrated bar. The height was compared with the new WHO (world health organization) child growth standards, 2006 reference data for that particular age and sex to get height for age. Children below 24months of age (below $85 \mathrm{~cm}$ ) were measured in a recumbent position by using a length board. In addition the correct age of a child was elicited from the child's vaccination card and mother's recall.

\section{Data quality assurance}

Before actual data collection recruitment of educated individuals who had previous experience of data collection and who speak local languages spoken in the study area were performed. In addition one week intensive training was given to the interviewers and supervisors regarding to the objectives of the study, administration of the tool, anthropometric measurements and ethical issue. On daily basis collected information was checked for completeness and consistency by principal investigator and possible errors identified was returned to the data collectors for correction.

\section{Statistical analysis}

Data was double entered in to Epi Data version 3.1 statistical package software and exported to Statistical Package for Social Sciences (SPSS) software version 20.0 for analysis of descriptive statistics and statistical inferences. Both bivariate and multivariate logistic regression analysis was performed to identify the factors that are associated with child chronic under nutritional status (stunting). All the variables with $p$ value $\leq 0.2$ at the bivariate analysis were entered into the multivariable logistic regression model. In addition, repeatedly reported risk factors of poor nutritional status were entered into the model regardless of the p-value. In multivariable logistic regression analysis OR and $95 \% \mathrm{CI}$ was estimated to reveal the strength of association and a "p" value less than 0.05 was used to declare the statistical significance.

\section{Ethical consideration}

The design of this study was approved by Ethical Review Committee of Wollega University. Permission was also obtained from the concerned bodies of East Wollega Zonal Health Department and the responsible administrative bodies of selected districts and administrative Kebeles. Name and other personal identifiers were not recorded on data collection form to keep confidentiality and were also used for this study purpose only. They were given full right to leave/to refuse to take part at any stage of the interview. But their participation in this study was essential to achieving the stated objectives that cannot be achieved without the participation of them. Informed verbal consent was obtained from the participants as witnessed by data collectors name and signature.

\section{Results}

A total of 981 children with their mothers were included and used in the analysis of this study making the overall response rate of $94.5 \%$. Majority of studied children (224) fell in the age group $12-23$ months. The mean age of cases and controls with SD were $30.54 \pm 14.02$ and $28.9 \pm 15.7$ respectively. Among the cases of studied children $56.1 \%$ were male and $43.9 \%$ were female. About $41.4 \%$ of mothers and $31.8 \%$ of fathers were illiterate. Illiterate mothers and fathers among cases were lower compared in controls. Almost equal proportion of mothers of cases $(71.4 \%)$ and controls $(70.1 \%)$ were housewife. About $67.6 \%$ of fathers of cases and $75.1 \%$ of fathers of controls were farmers. About $82 \%$ of study participants are Oromo in ethnicity (Table 1).

Table I Demographic and socio-economic characteristics of the sample and their mothers in east Wollega

*: single, divorced, widowed; **: driver, daily laborer, government employee; ***:Tigre, Guragie

\begin{tabular}{|c|c|c|c|c|}
\hline Variables & Coding categories & Cases (\%) & Controls (\%) & Total (\%) \\
\hline \multirow{4}{*}{ Sex of Children $(n=981$} & Male & 194 (56.1\%) & $313(49.3 \%)$ & 507 (5I.7\%) \\
\hline & Female & I52 (43.9\%) & 322 (50.7\%) & 474 (48.3\%) \\
\hline & $6-11$ & 25 (7.2\%) & $106(16.7 \%)$ & $131(13.4 \%)$ \\
\hline & 23-Dec & $90(26.0 \%)$ & 134 (2|.2\%) & $224(22.9 \%)$ \\
\hline \multirow{6}{*}{ Age of Children $(n=97$} & $24-35$ & 81 (23.4\%) & 121 (19.1\%) & 202 (20.6\%) \\
\hline & & & & \\
\hline & $36-47$ & 73 (21.1\%) & 138 (21.8\%) & $211(21.6 \%)$ \\
\hline & $48-59$ & 77 (22.3\%) & I 34 (2|.2\%) & $211(21.6 \%)$ \\
\hline & Mean age \pm SD & $30.54 \pm 14.02$ & $28.9 \pm 15.7$ & $29.49 \pm 15.14$ \\
\hline & I & 107 (30.9\%) & 227 (35.7\%) & $334(34.0 \%)$ \\
\hline \multirow[t]{2}{*}{ Birth Order $(n=981)$} & $2-4$ & $166(48.0 \%)$ & $316(49.8 \%)$ & $482(49.1 \%)$ \\
\hline & $>=5$ & 73 (21.1\%) & 92 (14.5\%) & 165 (I6.8\%) \\
\hline
\end{tabular}




\begin{tabular}{|c|c|c|c|c|}
\hline Variables & Coding categories & Cases (\%) & Controls (\%) & Total (\%) \\
\hline \multirow{3}{*}{ Birth Interval $(n=981)$} & No previous birth & $107(30.9 \%)$ & $227(35.7 \%)$ & $334(34.0 \%)$ \\
\hline & $<24$ months & $5 \mathrm{I}(14.7 \%)$ & 70 ( $11.0 \%)$ & $121(12.3 \%)$ \\
\hline & $>=24$ months & $188(54.3 \%)$ & $338(53.2 \%)$ & $526(53.6 \%)$ \\
\hline \multirow{3}{*}{ Perceived Size of Baby at Birth $(n=957)$} & Large & $82(24.6 \%)$ & I5I (24.2\%) & $233(24.3 \%)$ \\
\hline & Average & $178(53.3 \%)$ & $364(58.4 \%)$ & $542(56.6 \%)$ \\
\hline & Small & $74(22.2 \%)$ & $108(17.3 \%)$ & $182(19.0 \%)$ \\
\hline \multirow{3}{*}{ Mothers Age at First Birth $(n=98 I)$} & $<18$ years & $134(38.7 \%)$ & $240(37.8 \%)$ & $374(38.1 \%)$ \\
\hline & $>=18$ years & $212(61.3 \%)$ & $395(62.2 \%)$ & 607 (61.9\%) \\
\hline & $<18$ years & $13(3.8 \%)$ & $30(4.7 \%)$ & $43(4.4 \%)$ \\
\hline \multirow{3}{*}{ Mother Age at Birth of Index Child $(n=98 I)$} & I8-24 years & $148(42.8 \%)$ & $286(45.0 \%)$ & $434(44.2 \%)$ \\
\hline & $25-31$ years & $120(34.7 \%)$ & $233(36.7 \%)$ & $353(36.0 \%)$ \\
\hline & $>=32$ years & $65(18.8 \%)$ & $86(13.5 \%)$ & I5I (I5.4\%) \\
\hline \multirow{2}{*}{ Current Marital Status $(\mathrm{n}=98 \mathrm{I})$} & Married & $324(93.6 \%)$ & $598(94.2 \%)$ & $922(94.0 \%)$ \\
\hline & Others* & $22(6.4 \%)$ & 37 (5.8\%) & $59(6.0 \%)$ \\
\hline \multirow{2}{*}{ Maternal Education Status ( $\mathrm{n}=98 \mathrm{I})$} & Illiterate & $138(39.9 \%)$ & $268(42.2 \%)$ & 406 (4I.4\%) \\
\hline & Literate & $208(60.1 \%)$ & $367(57.8 \%)$ & 575 (58.6\%) \\
\hline \multirow{2}{*}{ Paternal Education Status ( $\mathrm{n}=98 \mathrm{I}$ ) } & Illiterate & $104(30.1 \%)$ & $208(32.8 \%)$ & $312(31.8 \%)$ \\
\hline & Literate & 242 (69.9\%) & 427 (67.2\%) & 669 (68.2\%) \\
\hline \multirow{2}{*}{ Mother's Occupation ( $\mathrm{n}=98 \mathrm{I})$} & Housewife & 247 (7I.4\%) & $445(70.1 \%)$ & $692(70.5 \%)$ \\
\hline & Working Mothers & $99(28.6 \%)$ & $190(29.9 \%)$ & $289(29.5 \%)$ \\
\hline \multirow{2}{*}{ Mother's Husband Occupation ( $\mathrm{n}=98 \mathrm{I})$} & Farmers & $234(67.6 \%)$ & $477(75.1 \%)$ & 711 (72.5\%) \\
\hline & Others** & 112 (32.4\%) & I 58 (24.9\%) & $270(27.5 \%)$ \\
\hline \multirow{3}{*}{ Ethnicity $(n=98 I)$} & Oromo & $286(82.7 \%)$ & $514(80.9 \%)$ & $800(81.5 \%)$ \\
\hline & Amhara & $49(14.2 \%)$ & $98(15.4 \%)$ & 147 (I5.0\%) \\
\hline & Others*** & II (3.2\%) & $23(3.6 \%)$ & $34(3.5 \%)$ \\
\hline \multirow{3}{*}{ Religion ( $\mathrm{n}=98 \mathrm{I}$ ) } & Orthodox & $15 \mid(43.6 \%)$ & 285 (44.9\%) & 436 (44.4\%) \\
\hline & Protestant & 117 (33.8\%) & I 89 (29.8\%) & 306 (31.2\%) \\
\hline & Muslim & 78 (22.5\%) & $|6|$ (25.4\%) & 239 (24.4\%) \\
\hline
\end{tabular}

About $86 \mathrm{HHs}$ are headed by female and the average family size is 4.7 persons with $\pm 1.64 \mathrm{SD}$ and $29.1 \%$ of $\mathrm{HHs}$ had more than five family sizes. About $22 \%$ of $\mathrm{HHs}$ had 2 under five year children and 10 HHs had 3 under five year children. Majority of the study participants were living in houses having corrugated iron sheet roof and earthen floor (Table 2).

Among the frequently reported problems in cases within 2 weeks preceding the study the higher proportion (47\%) were diarrhea followed by fever $(34 \%)$. For about $41 \%$ of studied cases the sources of drinking water were unprotected. Almost equal proportion of cases $(52 \%)$ and controls $(54 \%)$ had history of no colostrum feeding. Similarly for almost equal proportion of cases $(84 \%)$ and controls $(81 \%)$ the time of initiation of complementary foods were by the age of 4-6months (Table 3).

\section{Factors associated with stunting}

In bivariate logistic regression analysis male children $(\mathrm{COR}=1.3$
$95 \% \mathrm{CI}=1.009,1.708), 5^{\text {th }}$ and above birth $(\mathrm{COR}=1.6895 \% \mathrm{CI}=1.15$, 2.47 ), narrow birth interval ( $<24 \mathrm{months})(\mathrm{COR}=4.6995 \% \mathrm{CI}=1.61$, 13.66), children of mothers with no ANC follow up (COR $=1.8$ $95 \% \mathrm{CI}=1.14,2.93)$, bottle feeding $(\mathrm{COR}=1.8195 \% \mathrm{CI}=1.098,2.98)$, hand feeding $(\mathrm{COR}=1.6495 \% \mathrm{CI}=1.012,2.64)$, breast feeding for less than 2years $(\mathrm{COR}=1.6695 \% \mathrm{CI}=1.115,2.48)$, children with diarrhea $(\mathrm{COR}=1.3895 \% \mathrm{CI}=1.058,1.796)$, children in female headed $\mathrm{HHs}$ $(\mathrm{COR}=1.7695 \% \mathrm{CI}=1.13,2.75)$, HHs having more than one under five children $(\mathrm{COR}=1.4995 \% \mathrm{CI}=1.094,2.014)$, children of fathers having occupation other than farmer $(\mathrm{COR}=1.4595 \% \mathrm{CI}=1.08,1.93)$, children of $\mathrm{HHs}$ having relatively lower monthly income $(\mathrm{COR}=1.35$ $95 \% \mathrm{CI}=1.016,1.798)$ and lack of possession of agricultural land $(\mathrm{COR}=1.4595 \% \mathrm{CI}=1.089,1.93)$ were more likely to be chronically undernourished. On the other hand the occurrence of stunting was about $59 \%$ less likely among children aged 6-11months compared to those older children. The odds of stunting was about 34\% less likely in those children who currently breast feed compared to those under five children who currently not breast feed. The odds of stunting was 
$67.5 \%$ lower among children who started additional foods by the age of 4-6months and $77.5 \%$ lower in those children who started by the age of 7-12months compared to those who started by the age of $<4$ months. The occurrence of stunting was about $46 \%$ less likely in those children of $\mathrm{HHs}$ who dispose waste through burning, $46.6 \%$ less likely in those HHs who dispose through composting and about $42 \%$ less likely in those HHs who dispose through collecting in pit compared to those who dispose through open field (Table 4). In this study multivariate logistic regression analysis showed sex of children, birth order, birth interval, methods complementary feeding, duration of breast feeding, diarrhea, ownership of agricultural land and waste disposal methods were strongly significantly associated with the occurrence of stunting.

Table 2 Demographic and socio-economic characteristics of the studied children's households

$\mathrm{SD}$, standard deviation; BMI, body mass index; WC, waist circumference; $A C$, abdominal circumference; HC, hip circumference; RER, respiratory exchange ratio; $\mathrm{HR}$, hear rate

\begin{tabular}{|c|c|c|c|c|}
\hline Variables & Coding categories & Cases (\%) & Controls (\%) & Total (\%) \\
\hline \multirow{2}{*}{ Household Head ( $n=981)$} & Mothers & $4 \mathrm{l}(\mathrm{I} \mathrm{I} .8 \%)$ & $45(7.1 \%)$ & $86(8.8 \%)$ \\
\hline & Fathers & 305 (88.2\%) & $590(92.9 \%)$ & 895 (91.2\%) \\
\hline \multirow{2}{*}{ Family Size in a HH (n=98I) } & $2-5$ & $242(69.9 \%)$ & 454 (7I.5\%) & $696(70.9 \%)$ \\
\hline & $>5$ & $104(30.1 \%)$ & I8I (28.5\%) & $285(29.1 \%)$ \\
\hline \multirow{2}{*}{ Number of $<5$ Children in a $\mathrm{HH}(\mathrm{n}=98 \mathrm{I})$} & $\mathrm{I}$ & $25 \mathrm{I}(72.5 \%)$ & $506(79.7 \%)$ & $757(77.2 \%)$ \\
\hline & $2-3$ & 95 (27.5\%) & $129(20.3 \%)$ & $224(22.8 \%)$ \\
\hline \multirow{2}{*}{ Material of Roof of the House $(n=98 I)$} & Thatched & $89(25.7 \%)$ & I5I (23.8\%) & $240(24.5 \%)$ \\
\hline & Corrugated Iron sheet & $257(74.3 \%)$ & $484(76.2 \%)$ & $741(75.5 \%)$ \\
\hline \multirow{3}{*}{ Material of Floor of the House $(n=98 I)$} & Earthen/Soil & $289(83.5 \%)$ & 497 (78.3\%) & $786(80.1 \%)$ \\
\hline & Cemented & $52(15.0 \%)$ & $130(20.5 \%)$ & $182(18.6 \%)$ \\
\hline & Wooden & $5(1.4 \%)$ & $8(1.3 \%)$ & $13(1.3 \%)$ \\
\hline \multirow{2}{*}{ Presence of Windows $(n=98 I)$} & Yes & $324(93.6 \%)$ & 602 (94.8\%) & $926(94.4 \%)$ \\
\hline & No & $22(6.4 \%)$ & $33(5.2 \%)$ & $55(5.6 \%)$ \\
\hline \multirow[b]{2}{*}{ Kitchen Site $(n=980)$} & Inside Living Room & 44 (I2.7\%) & $62(9.8 \%)$ & $106(10.8 \%)$ \\
\hline & Separate & 302 (87.3\%) & 572 (90.2\%) & $874(89.2 \%)$ \\
\hline \multirow{3}{*}{ Monthly HH Income (in ETB, n=884) } & $<=1600$ & 126 (40.5\%) & 192 (33.5\%) & $318(36.0 \%)$ \\
\hline & & & & \\
\hline & $>1600$ & 185 (59.5\%) & $381(66.5 \%)$ & $566(64.0 \%)$ \\
\hline Decision Making on & Wife & 39 (11.3\%) & 50 (7.9\%) & 89 (9.1\%) \\
\hline \multirow{2}{*}{ Utilization of Money $(n=980)$} & Husband & | 44 (4I.6\%) & $282(44.5 \%)$ & $426(43.5 \%)$ \\
\hline & Both Jointly & $163(47.1 \%)$ & $302(47.6 \%)$ & $465(47.4 \%)$ \\
\hline \multirow{2}{*}{ Ownership of Agricultural Land $(n=98 I)$} & No & $116(33.5 \%)$ & $164(25.8 \%)$ & $280(28.5 \%)$ \\
\hline & Yes & $230(66.5 \%)$ & 47I (74.2\%) & $70 \mathrm{I}(7 \mathrm{I} .5 \%)$ \\
\hline
\end{tabular}

The odds of stunting in male children were about 2.5 times higher $(\mathrm{AOR}=2.45895 \% \mathrm{CI}=1.52,3.99)$ as compared to female counterparts. The risk of stunting among $5^{\text {th }}$ and above birth order children were 1.71 times higher $(\mathrm{AOR}=1.70795 \% \mathrm{CI}=1.02,2.857)$ compared to $1^{\text {st }}$ born children. The occurrence of stunting were about 5 times higher in those studied children with narrow birth interval ( $\mathrm{AOR}=4.69$ $95 \% \mathrm{CI}=1.613,13.66$ ) and 2.4 times higher in those children with 2 and above years birth interval ( $\mathrm{AOR}=2.42495 \% \mathrm{CI} 1.246,4.71)$ compared to those children with no previous birth. The odds of stunting were about 2.4times higher in those children whose mother uses hand $(\mathrm{AOR}=2.3995 \% \mathrm{CI}=1.226,4.67)$ and $\operatorname{cup}(\mathrm{AOR}=2.36795 \% \mathrm{CI}=1.04$, 5.38) for feeding additional foods and about 2.5times higher in those children whose mother uses bottle $(\mathrm{AOR}=2.4995 \% \mathrm{CI}=1.312,4.725)$ for feeding compared to those who uses spoon for feeding. Children who had breast feed for less than 2years were 2.2times at increased risk of stunting $(\mathrm{AOR}=2.1595 \% \mathrm{CI}=1.249,3.707)$ than those who breast feed for 2 and above years. Children with compliant of diarrhea within 2 weeks of the study were 2.4 times at increased risk of stunting $(\mathrm{AOR}=2.4495 \% \mathrm{CI}=1.42,4.19)$ compared with those with no diarrheal compliant. The odds of stunting was about 2 times higher in those children of HHs with no ownership of agricultural land (AOR=1.698 $95 \% \mathrm{CI}=1.035,2.785)$ compared to those who had agricultural land. Children of HHs who dispose waste through burning, composting and in pit respectively were $51.8 \%(\mathrm{AOR}=.48295 \% \mathrm{CI}=.228,1.021)$, $60.1 \% \quad(\mathrm{AOR}=.399 \quad 95 \% \mathrm{CI}=.223, .711)$ and $46.6 \% \quad(\mathrm{AOR}=.534$ $95 \% \mathrm{CI}=.288, .99)$ less likely to be stunted compared to those who dispose through open field (Table 4). 
Table 3 Health and health related characteristics as well as feeding practices of the sample and their mothers I: river, pond, unprotected spring; 2: public tap, private pipe, protected spring

\begin{tabular}{|c|c|c|c|c|}
\hline Variables & Coding categories & Cases (\%) & $\begin{array}{l}\text { Controls } \\
(\%)\end{array}$ & Total (\%) \\
\hline \multirow{2}{*}{ Diarrhea, Preceding 2wks ( $\mathrm{n}=98 \mathrm{I})$} & Yes & $164(47.4 \%)$ & $251(39.5 \%)$ & $415(42.3 \%)$ \\
\hline & No & $182(52.6 \%)$ & $384(60.5 \%)$ & $566(57.7 \%)$ \\
\hline \multirow{2}{*}{ Fever, Preceding 2 wks $(n=870)$} & Yes & $107(34.2 \%)$ & $182(32.7 \%)$ & $289(33.2 \%)$ \\
\hline & No & $206(65.8 \%)$ & $375(67.3 \%)$ & $58 I(66.8 \%)$ \\
\hline \multirow{2}{*}{ Respiratory Diseases, Preceding 2wks $(n=870)$} & Yes & $52(16.6 \%)$ & $80(14.4 \%)$ & $132(\mid 5.2 \%)$ \\
\hline & No & $26 \mathrm{I}(83.4 \%)$ & $477(85.6 \%)$ & 738 (84.8\%) \\
\hline \multirow{2}{*}{ Immunization Status $(\mathrm{n}=98 \mathrm{I})$} & Immunized & $292(84.4 \%)$ & $548(86.3 \%)$ & $840(85.6 \%)$ \\
\hline & Not Immunized & $54(15.6 \%)$ & 87 (I3.7\%) & I4I (I4.4\%) \\
\hline \multirow{2}{*}{ Sources of Drinking Water $(n=98 I)$} & Unprotected Sources I & I 4 I (40.8\%) & $282(44.4 \%)$ & $423(43.1 \%)$ \\
\hline & Protected Sources 2 & 205 (59.2\%) & $353(55.6 \%)$ & $558(56.9 \%)$ \\
\hline \multirow{3}{*}{ Presence of Latrine $(n=979)$} & No & $106(30.7 \%)$ & $195(30.8 \%)$ & $30 \mathrm{I}(30.7 \%)$ \\
\hline & $\begin{array}{l}\text { Private pit/Wooden } \\
\text { slab }\end{array}$ & $198(57.4 \%)$ & $364(57.4 \%)$ & $562(57.4 \%)$ \\
\hline & $\begin{array}{l}\text { Private pit/Cement } \\
\text { slab }\end{array}$ & $4 \mathrm{l}(\mathrm{I} I .9 \%)$ & $75(\mathrm{I} I .8 \%)$ & I I 6 (II.8\%) \\
\hline \multirow{4}{*}{ Waste Disposal Methods $(n=98 I)$} & Burning & $78(22.5 \%)$ & $153(24.1 \%)$ & $231(23.5 \%)$ \\
\hline & Composting & $162(46.8 \%)$ & $319(50.2 \%)$ & $481(49.0 \%)$ \\
\hline & In pit & $67(19.4 \%)$ & $122(19.2 \%)$ & $189(19.3 \%)$ \\
\hline & Open field disposal & 39 (II.3\%) & $4 \mathrm{I}(6.5 \%)$ & $80(8.2 \%)$ \\
\hline \multirow{2}{*}{ Antenatal Clinic Visits (Index Child, n=98I) } & No ANC follow up & $37(10.7 \%)$ & $39(6.1 \%)$ & $76(7.7 \%)$ \\
\hline & Had ANC follow up & $309(89.3 \%)$ & $596(93.9 \%)$ & $905(92.3 \%)$ \\
\hline \multirow{2}{*}{ Pre-Lacteal Feeding Practices $(n=98 I)$} & No & $243(70.2 \%)$ & $423(66.6 \%)$ & $666(67.9 \%)$ \\
\hline & Yes & $103(29.8 \%)$ & $212(33.4 \%)$ & $315(32.1 \%)$ \\
\hline \multirow{2}{*}{ Colostrum Feeding $(n=98 I)$} & No & $179(5 \mathrm{I} .7 \%)$ & $340(53.5 \%)$ & $519(52.9 \%)$ \\
\hline & Yes & $167(48.3 \%)$ & $295(46.5 \%)$ & $462(47.1 \%)$ \\
\hline \multirow{3}{*}{ Currently BF (n=98I) } & $>4$ times & $102(29.5 \%)$ & $190(29.9 \%)$ & $292(29.8 \%)$ \\
\hline & I-4 times & 145 (4I.9\%) & $307(48.3 \%)$ & $452(46.1 \%)$ \\
\hline & Not currently BF & 99 (28.6\%) & 138 (21.7\%) & $237(24.2 \%)$ \\
\hline \multirow{3}{*}{ Age initiated for CF $(n=760)$} & $<4$ months & $9(3.3 \%)$ & $5(1.0 \%)$ & $14(1.8 \%)$ \\
\hline & 4-6months & $229(83.6 \%)$ & $392(80.7 \%)$ & $621(81.7 \%)$ \\
\hline & $7-12$ months & $36(13.1 \%)$ & $89(18.3 \%)$ & $125(16.4 \%)$ \\
\hline \multirow{4}{*}{ Methods of CF $(n=758)$} & Cup & 85 (31.2\%) & 159 (32.7\%) & $244(32.2 \%)$ \\
\hline & Bottle & $69(25.4 \%)$ & IOI (20.8\%) & $170(22.4 \%)$ \\
\hline & Hand & 84 (30.9\%) & $136(28.0 \%)$ & $220(29.0 \%)$ \\
\hline & Spoon & $34(12.5 \%)$ & $90(18.5 \%)$ & $124(16.4 \%)$ \\
\hline \multirow{2}{*}{ Duration of $B F(n=560)$} & $<24$ months & 59 (28.9\%) & 70 (19.7\%) & $129(23.0 \%)$ \\
\hline & $>=24$ months & $145(7 \mid .1 \%)$ & $286(80.3 \%)$ & 431 (77.0\%) \\
\hline \multirow{2}{*}{ Presence of Feeding Practices during Illness $(n=98 I)$} & No & I 59 (46.0\%) & $260(40.9 \%)$ & 419 (42.7\%) \\
\hline & Yes & $187(54.0 \%)$ & 375 (59.1\%) & $562(57.3 \%)$ \\
\hline \multirow{3}{*}{$\begin{array}{l}\text { Hand Wash during Preparation and Feeding of Child and Herself } \\
(n=959)\end{array}$} & Using Water only & $74(21.6 \%)$ & $129(20.9 \%)$ & $203(21.2 \%)$ \\
\hline & Using Soap Sometimes & $267(77.8 \%)$ & $483(78.4 \%)$ & $750(78.2 \%)$ \\
\hline & NoWash & $2(0.6 \%)$ & $4(0.6 \%)$ & $6(0.6 \%)$ \\
\hline
\end{tabular}


Table 4 Factors which show association with stunting of under five children in the study area; bivariate and multivariate logistic regression analysis result *: $\mathrm{p}<0.05$; **: $\mathrm{p}<0.005 ; \mathrm{COR}$, crude odds ratio; $\mathrm{AOR}$, adjusted odds ratio; $\mathrm{Cl}$, confidence interval

\begin{tabular}{|c|c|c|c|c|c|}
\hline Variables & Coding categories & Cases & Controls & COR $(95 \% \mathrm{Cl})$ & AOR $(95 \% \mathrm{Cl})$ \\
\hline \multirow{2}{*}{ Sex of Children $(n=98 I)$} & Male & 194 & 313 & $1.3(1.009, \mathrm{I} .708)^{*}$ & $2.458(1.515,3.989)^{* *}$ \\
\hline & Female & 152 & 322 & I & I \\
\hline \multirow{5}{*}{ Age of Children $(n=979)$} & $6-11$ & 25 & 106 & $.410(.244, .689)^{* *}$ & $.000(.000)$ \\
\hline & $12-23$ & 90 & 134 & $1.169(.794,1.721)$ & I.I I $(.378,3.268)$ \\
\hline & $24-35$ & 81 & 121 & I.I $65(.783,1.733)$ & $.874(.4 \mid 2,1.853)$ \\
\hline & $36-47$ & 73 & 138 & $.921(.618,1.372)$ & $.729(.385, \mathrm{I} .382)$ \\
\hline & $48-59$ & 77 & 134 & 1 & I \\
\hline \multirow{3}{*}{ Birth Order $(n=98 I)$} & I & 107 & 227 & I & I \\
\hline & $4-\mathrm{Feb}$ & 166 & 316 & I. I I $4(.828,1.5)$ & I.I $3(.743,1.72)$ \\
\hline & $>=5$ & 73 & 92 & $1.68(1.147,2.47)^{*}$ & $\mathrm{I} .707(\mathrm{I} .02,2.857)^{*}$ \\
\hline \multirow{3}{*}{ Birth Interval $(n=981)$} & No Previous Birth & 107 & 227 & I & I \\
\hline & $<24$ months & 51 & 70 & $1.546(1.008,2.37)^{*}$ & $4.693(1.613,13.655)^{* *}$ \\
\hline & $>=24$ months & 188 & 338 & I.I8 (.882, I.578) & $2.424(1.246,4.7 \mid 4)^{*}$ \\
\hline \multirow{2}{*}{ Antenatal Clinic Visits (Index Child, n=98I) } & No ANC Follow Up & 37 & 39 & $\mathrm{I} .83(\mathrm{I} .143,2.929)^{*}$ & $\mathrm{I} .652(.796,3.428)$ \\
\hline & Had ANC Follow Up & 309 & 596 & I & I \\
\hline \multirow{3}{*}{ Currently BF (n=98I) } & $>4$ times & 102 & 190 & $.748(.526,1.065)$ & $.612(.213,1.758)$ \\
\hline & I-4 times & 145 & 307 & $.658(.476, .911)^{*}$ & $.534(.128,2.22)$ \\
\hline & Not currently BF & 99 & 138 & I & $\mathrm{I}$ \\
\hline \multirow{3}{*}{ Age Initiated for CF $(n=760)$} & $<4$ months & 9 & 5 & I & I \\
\hline & 4-6months & 229 & 392 & $.325(.107, .980)^{*}$ & $.000(.000)$ \\
\hline & $7-12$ months & 36 & 89 & $.225(.07, .7 \mid 7)^{*}$ & $.000(.000)$ \\
\hline \multirow{4}{*}{ Methods of CF $(n=758)$} & Cup & 85 & 159 & $1.415(.88,2.274)$ & $2.367(1.04,5.38)^{*}$ \\
\hline & Bottle & 69 & 101 & $1.808(1.098,2.98)^{*}$ & $2.49(1.312,4.725)^{* *}$ \\
\hline & Hand & 84 & 136 & $1.635(1.012,2.64)^{*}$ & $2.393(I .226,4.67 I)^{*}$ \\
\hline & Spoon & 34 & 90 & I & I \\
\hline \multirow{2}{*}{ Duration of $B F(n=560)$} & $<24$ months & 59 & 70 & $\mathrm{I} .662(\mathrm{I} . \mathrm{I} \mid \mathrm{5}, 2.480)^{*}$ & $2.152(1.249,3.707)^{*}$ \\
\hline & $>=24$ months & 145 & 286 & 1 & I \\
\hline \multirow{2}{*}{ Diarrhea, Preceding 2wks ( $\mathrm{n}=98 \mathrm{I})$} & Yes & 164 & 251 & $\mathrm{I} .379(\mathrm{I} .058, \mathrm{I} .796)^{*}$ & $2.44 \mathrm{I}(\mathrm{I} .42 \mathrm{I}, 4.19)^{* *}$ \\
\hline & No & 182 & 384 & I & I \\
\hline \multirow{2}{*}{ Household Head (n=98I) } & Mothers & 41 & 45 & $1.76(1.129,2.75)^{*}$ & $1.611(.776,3.344)$ \\
\hline & Fathers & 305 & 590 & $\mathrm{I}$ & I \\
\hline \multirow{2}{*}{ Number of $<5$ Children in a $\mathrm{HH}(n=98 \mathrm{I})$} & $\mathrm{I}$ & 251 & 506 & 1 & $\mathrm{I}$ \\
\hline & $2-3$ & 95 & 129 & $1.485(1.094,2.014)^{*}$ & I. $198(.68,2.108)$ \\
\hline \multirow{2}{*}{ Mother's Husband Occupation (n=98I) } & Farmers & 234 & 477 & I & I \\
\hline & Others** & 112 & 158 & $1.445(\mathrm{I} .08, \mathrm{I} .928)^{*}$ & $1.104(.616,1.977)$ \\
\hline \multirow{2}{*}{ Monthly HH Income (in ETB, n=884) } & $<=1600$ & 126 & 192 & I.352 (I.016, I.798)* & $\mathrm{I} .084(.572,2.057)$ \\
\hline & $>1600$ & 185 & 381 & I & I \\
\hline \multirow{2}{*}{ Ownership of Agricultural Land ( $\mathrm{n}=98 \mathrm{I})$} & No & 116 & 164 & $1.448(1.089,1.927)^{*}$ & $1.698(1.035,2.785)^{*}$ \\
\hline & Yes & 230 & $47 \mid$ & I & I \\
\hline
\end{tabular}




\begin{tabular}{llllll}
\hline Table continued... & Coding categories & Cases & Controls & COR (95\%Cl) & AOR (95\%CI) \\
\hline Variables & Burning & 78 & 153 & $.536(.32, .898)^{*}$ & $.482(.228,1.02 I)$ \\
Waste Disposal Methods $(\mathrm{n}=98 \mathrm{I})$ & Composting & 162 & 319 & $.534(.33, .86)^{*}$ & $.399(.223, .7 \mathrm{II})^{* *}$ \\
& In pit & 67 & 122 & $.577(.34, .98)^{*}$ & $.534(.288, .99)^{*}$ \\
\hline
\end{tabular}

\section{Discussion}

In this study among the demographic and socioeconomic factors; being male children, higher birth order, narrow birth interval and lack of ownership of agricultural land is strongly leading to chronic under nutritional status of children.

The odds of stunting were significantly higher in male children than female counterparts which are consistent with previous studies..$^{9-21}$ This may be attributed to diseased status during the study period. While conducting this study compliant of diarrhea, fever, malaria and typhoid were more prevalent in male children.

The current study showed, $5^{\text {th }}$ and above birth order children were at significantly increased risk of stunting compared to $1^{\text {st }}$ born children. The finding is supported by previous study conducted elsewhere. ${ }^{22}$ This could be explained by the fact that, those HHs with high birth order of studied children may have large family size where distribution of resources including foods and child health care is reduced. In addition cultural practice in Ethiopia in general and in the study area in particular revealed more care and attention is given for the $1^{\text {st }}$ born children.

The finding of this study revealed the risk of stunting were significantly higher among those studied children born to mothers after an interval of less than 24 months of his or her older children compared to those born after an interval of greater and equal to 24 months of his or her older children. The finding is consistent with previous local large scale studies. ${ }^{23}$ This could be explained by occurrence of pregnancy in less than two years after previous birth impacts recovery of nutritional and health status of mothers that leads to low birth weight newborn. Low birth weight infant may be at risk of experiencing growth failure during childhood and adulthood and may impact the next generation. The higher occurrence of narrow birth interval in the study area may suggest that the community had lower income as higher socioeconomic status may be related with possibility of getting improved healthcare and feeding practices as well as greater purchasing power to family planning services.

Lack of ownership of agricultural land significantly increases the risk of stunting, which is supported by previous studies conducted elsewhere. ${ }^{11}$ Livelihoods of people of most of the HHs in rural areas of Ethiopia in general and in the study area in particular are depends on agriculture or cultivation of crops. Therefore land is one of the key inputs for cultivation of crops. In other words, children of HHs with farmland ownership might have higher income which is used for better living condition.

In the present study, among health and health related factors and infant and young child feeding practices; open field waste disposal, diarrhea, short duration of breast feeding and mothers utilization of bottle and hand for feeding of additional foods were strong predictors of chronic undernutrition in children.

Children of HHs which dispose wastes through open field were at increased risk of stunting. Open field waste disposal is the cause of poor environmental sanitation and personal hygiene. When the growing children are exposed to open field wastes, they may ingest high amount of pathogens like bacteria, virus, fungi or parasites through ingestion of fingers or household materials in the oral cavity which leads to infection of intestine. This impacts nutritional status of children by; decreased appetite, reduced nutrient absorption and increased nutrient loss. Thus hygienic toilets, access to clean water and proper hand washing are key actions that need to be implemented in the study area to curb the problem of stunting.

The association between diarrhea and undernutrition is two way. That is diarrhea can cause and become consequences of undernutrition. The present study revealed children with diarrhea were at significantly increased risk of stunting compared to those without diarrhea. The finding is in line with previous studies. ${ }^{1,16,21}$ This could be attributed to children with diarrhea may have reduced dietary intake, poor absorption of nutrients and increased nutrient disposal. Moreover children with undernutrition could have diminished immunity which intern leads to infection including diarrhea.

Breast feeding helps to ensure normal health of children as it provides the right balance of nutrients. The present study come with breast feeding for less than 24 months significantly increases the risk of stunting. This could be due to lack of essential nutrients and antibodies gained from the breast milk. Antibodies obtained from the breast feeding protect against different diseases mainly diarrhea and respiratory infections which leads to diminished appetite and thereby decreased intake of foods. In addition in the presence of short duration of breast feeding there is poor psychomotor, emotional and social development of the child due to inadequate skin to skin contact between the mother and the child.

That is skin to skin contact encouraged by breast feeding offer the chance for babies to develop greater emotional security and to enhance bonding. In contrary previous local study conducted elsewhere ${ }^{14}$ reported prolonged duration of breast feeding significantly increases the risk of stunting. This may be attributed to inappropriate complementary feeding practices of the previous study area. That is time of initiation of complementary feeding among the previous children may be in older age. Thus to enhance good nutritional status of children both larger duration of breast feeding and appropriate complementary feeding is necessarily.

Children of mothers who use bottle and hand for feeding of complementary foods were at significantly higher risk of stunting which is consistent with previous many local studies. ${ }^{12,14,17}$ This could be attributed to high chance of contamination with pathogens and ingestion of microorganisms along with the food eaten which intern leads to infection and undernutrition.

In the present study maternal educational status didn't show significant association with chronic nutritional status of children, which is in line with previous local study. ${ }^{13}$ On the other hand the finding of this study is in contrary to the result of many other previous studies conducted elsewhere. 12,19,21,22,24 $^{2}$ 
This study might have the following limitations. As the study was questionnaire based, questions that required a good memory were vulnerable to recall bias. In addition because of interview nature of the study, it could offer a chance for interviewer bias. Lastly, the study is predisposed to errors of anthropometric measurement that might lead to misclassification of children's nutritional status. However necessary efforts were made on study procedures which include, intensive training of research team, repeated measurement and close supervision of the data collectors during the field work to decrease anthropometric measurement errors. In addition efforts were made to get correct age of the children like looking of child's vaccination card or discharge delivery card and mother's recall. Mother's recall especially recall of illiterate mother was assisted by referring to local events.

\section{Conclusion and recommendations}

Stunting was significantly associated with male sex, high birth order, narrow birth interval, lack of possession of agricultural land, poor sanitation, diarrhea, inappropriate IYCF (infant and young child feeding) practices like; short duration of breast feeding and mothers utilization of bottle and hand for feeding additional foods. Thus organized efforts aimed at improving sanitary condition and IYCF practices of the rural community is necessarily in order to tackle the problem of undernutrition in children. More over mothers needs to be encouraged to space births through use of family planning services.

\section{Declaration}

\section{Ethical consideration}

The design of this study was approved by Ethical Review Committee of Wollega University. Permission was also obtained from the concerned bodies of East Wollega Zonal Health Department and the responsible administrative bodies of selected districts and administrative Kebeles. Name and other personal identifiers were not recorded on data collection form to keep confidentiality and were also used for this study purpose only. They were given full right to leave/to refuse to take part at any stage of the interview. But their participation in this study was essential to achieving the stated objectives that cannot be achieved without the participation of them. Informed verbal consent was obtained from the participants as witnessed by data collectors name and signature.

\section{Consent for publication}

Not applicable

\section{Availability of data and materials}

The corresponding author may provide if necessarily

\section{Funding}

Wollega university health research publication directorate; grant number Ref/w/u: 87, 629/Res/Tech.T1-26/08. Official website www. wuni.edu.et. The funding body has no role in the design of the study and collection, analysis, and interpretation of data and in writing the manuscript.

\section{Authors' contribution}

AT: principal investigator involved in conception and designing of the study, collection, entry, analysis, interpretation of the data, prepare the manuscript.
MC: involved in designing of the study, analysis and interpretation of data as well as manuscript preparation.

EA: involved in designing of the study, analysis and interpretation of data as well as manuscript preparation.

\section{Acknowledgements}

We would like to thank Wollega University for giving us such opportunity in research work and financial support. Our appreciation also goes to the staffs of our college who supported us throughout the development of this research report.

\section{Conflict of interest}

The author declares no conflict of interest.

\section{References}

1. de Onis M, Monteiro C, Akre J, et al. The worldwide magnitude of protein-energy malnutrition: an overview from the WHO global database on child growth. Bulletin of the World Health Organization. 1993;71:703-712.

2. Physical status: the use and interpretation of anthropometry. Report of a WHO Expert Committee. Switzerland: World Health Organization; 1995.

3. Levels \& trends in child malnutrition: UNICEF-WHO-The World Bank Joint Child Malnutrition Estimates. 2012.

4. Children Malnutrition and Horizontal Inequalities in Sub-Saharan Africa: A Focus on Contrasting Domestic Trajectories UNDP. 2012.

5. Ethiopia Demographic and Health Survey 2011. USA: Central Statistical Agency, ICF International; 2012.

6. Ethiopia Mini Demographic and Health Survey 2014. Ethiopia: Central Statistical Agency; 2014.

7. Todd Benson, Meera Shekar. Trends and Issues in Child Undernutrition. Disease and Mortality in Sub-Saharan Africa. 2nd ed. USA: World Bank; 2006.

8. Macro ORC. Ethiopia Demographic and Health Survey 2000. USA: Central Statistical Authority, ORC Macro; 2001.

9. Ayenigbara GO. Malnutrition among children in the sahel region: causes, consequences and prevention. International Journal of Nutrition and Food Sciences. 2013;2(3):116-121.

10. Blössner M, Mercedes de Onis. Malnutrition: Quantifying the health impact at national and local levels. Environmental Burden of Disease Series, No. 12. Switzerland: World Health Organization WHO; 2005.

11. Tadiwos Zewdie DA. Determinants of child malnutrition: empirical evidence from Kombolcha District of Eastern Hararghe Zone, Ethiopia. Quarterly Journal of International Agriculture. 2013;52(4):357-372.

12. Solomon Demissie AW. Magnitude and Factors Associated with Malnutrition in Children 6-59 Months of Age in Pastoral Community of Dollo Ado District, Somali Region, Ethiopia. Science Journal of Public Health. 2013;1(4):175-183.

13. Edris M. Assessment of nutritional status of preschool children of Gumbrit, North West Ethiopia. Ethiopian Journal of Health Development. 2007;21(2):125-129.

14. Beka Teshome, Kogi-Makau W, Zewditu Getahun, et al. Magnitude and determinants of stunting in children under five years of age in food surplus region of Ethiopia:The case of West Gojjam Zone. Ethiopian Journal of Health Development. 2009;23(2):98-106. 
15. Girmay Medhin CH, Michael Dewey, Atalay Alem, et al. Prevalence and predictors of undernutrition among infants aged six and twelve months in Butajira, Ethiopia:The P-MaMiE Birth Cohort. BMC Public Health. 2010;10:27.

16. Behailu Tariku AM, Mache Tsadik, Girma Azene. Prevalence and Risk Factors of Child Malnutrition in Community Based Nutrition Program Implementing and Non implementing Districts from South East Amhara, Ethiopia. Open Access Library Journal. 2014;1:1-17.

17. Teshale Fikadu, Sahilu Assegid, Lamessa Dube. Factors associated with stunting among children of age 24 to 59 months in Meskan district, Gurage Zone, South Ethiopia:a case-control study. BMC Public Health. 2014;14:800.

18. Gudina Egata, Yemane Berhane, Alemayehu Worku. Predictors of acute undernutrition among children aged 6 to 36 months in east rural Ethiopia:a community based nested case - control study. $B M C$ Pediatrics. 2014;14:91

19. Correia LL, Silva AC, Campos JS, et al. Prevalence and determinants of child undernutrition and stunting in semiarid region of Brazil. Rev Saude Publica. 2014;48(1):19-28.
20. Ramli, Agho KE, Inder KJ, et al. Prevalence and risk factors for stunting and severe stunting amongunder-fives in North Maluku province of Indonesia. BMC Pediatris. 2009;9:64.

21. Makoka PK, Makoka D. Trends and determinants of undernutrition among young Kenyan children: Kenya Demographic and Health Survey; 1993, 1998, 2003 and 2008-2009. Public Health Nutr. 2012;15(9):1715-1727.

22. Benta A Abuya, James Ciera, Elizabeth Kimani-Murage. Effect of mother's education on child's nutritional status in the slums of Nairobi. BMC Pediatrics. 2012;12:80.

23. Headey D. An analysis of trends and determinants of child undernutrition in Ethiopia, 2000-2011. International Food Policy Research Institute; 2014. 27 p.

24. Kavosi E, Hassanzadeh Rostami Z, Kavosi Z, et al. Prevalence and determinants of under-nutrition among children under six:a crosssectional survey in Fars province, Iran. Int $J$ Health Policy Manag. 2014;3(2):71-76 